Buletin Ilmiah Mat. Stat. danTerapannya (Bimaster)

Volume 09, No. 2 (2020), hal 311-318.

\title{
MENGKONSTRUKSI FUNGSI GREEN PADA PERSAMAAN DIFERENSIAL LINEAR ORDE $n$ DENGAN METODE TRANSFORMASI SUMUDU
}

\author{
Maisurah, Helmi, Yudhi
}

\section{INTISARI}

Fungsi Green merupakan salah satu metode yang dapat menyelesaikan persamaan diferensial biasa linear nonhomogen. Akan tetapi, fungsi Green harus dikonstruksi terlebih dahulu. Tujuan dari penelitian ini yaitu mengkonstruksi fungsi Green pada persamaan diferensial linear orde $n$ nonhomogen melalui metode transformasi Sumudu. Persamaan diferensial biasa linear orde $n$ nonhomogen dengan syarat awal $y^{(n-1)}(0)=y^{(n-2)}(0)=\cdots=y(0)=0$ ditransformasi dengan transformasi Sumudu. Kemudian dikonstruksi ke bentuk $Y(z)=z B(z) W(z)$ dengan $B(z)$ merupakan transformasi dari $b(x)$ dan $W(z)$ merupakan transformasi dari $w(x)$ dan ditransformasi dengan invers transformasi Sumudu, sehingga diperoleh fungsi Green

$$
w(x)=\mathbb{S}^{-1}\left[\frac{z^{n-1}}{a_{n}+a_{n-1} z+\cdots+a_{1} z^{n-1}+a_{0} z^{n}}\right] .
$$

Kata Kunci : Persamaan diferensial, Transformasi Sumudu, dan Fungsi Green.

\section{PENDAHULUAN}

Matematika merupakan salah satu cabang ilmu yang mempunyai peranan penting bagi ilmu pengetahuan lainnya seperti Fisika, Biologi, Kimia, Ekonomi, dan lain sebagainya. Persamaan diferensial merupakan bagian dari ilmu matematika yang mempunyai peranan penting dalam ilmu pengetahuan tersebut. Ada dua jenis persamaan diferensial yang dikenal yaitu Persamaan Diferensial Biasa (PDB) dan Persamaan Diferensial Parsial (PDP). Persamaan diferensial biasa yaitu persamaan yang hanya melibatkan satu variabel bebas sedangkan persamaan diferensial parsial yaitu persamaan yang melibatkan lebih dari satu variabel bebas [1].

Suatu fungsi $f$ dikatakan penyelesaian persamaan diferensial jika persamaan itu dipenuhi ketika $y=f(x)$ dan turunan-turunannya disubstitusi ke dalam persamaan diferensial. Persamaan diferensial linear orde $n$ dapat diklasifikasikan berdasarkan kehomogenan, yaitu PDB linear homogen dan PDB linear nonhomogen. PDB linear nonhomogen memiliki penyelesaian umum yaitu $y=y_{h}+y_{p}$, dengan $y_{h}$ merupakan penyelesaian homogen dan $y_{p}$ merupakan penyelesaian nonhomogen. Persamaan diferensial linear orde $n$ nonhomogen dengan koefisien konstan seringkali diselesaikan dengan metode koefisien tak tentu, variasi parameter, metode invers operator dan lain sebagainya. Selain metode tersebut persamaan diferensial linear orde $n$ nonhomogen dengan koefisien konstan juga dapat diselesaikan dengan metode fungsi Green.

Fungsi Green pertama kali dipublikasi oleh seorang Matematikawan berkebangsaan Inggris yang bernama George Green [2]. Salah satu kegunaan fungsi Green yaitu untuk menyelesaikan persamaan diferensial. Fungsi Green dapat digunakan untuk menentukan solusi khusus dari suatu persamaan diferensial, akan tetapi mengkonstruksi terlebih dahulu bentuk dari fungsi Green untuk persamaan diferensial linear orde $n$ nonhomogen tersebut.

Konstruksi fungsi Green dapat dilakukan dengan beberapa metode. Diantaranya, fungsi Green dikonstruksi dengan metode transformasi Laplace [3]. Selain itu, fungsi Green juga dapat dikonstruksi dengan metode variasi parameter [4]. Pada penelitian ini, konstruksi fungsi Green ditentukan menggunakan metode transformasi Sumudu. Metode transformasi Sumudu merupakan transformasi yang identik dengan transformasi Laplace. Metode ini pertama kali diperkenalkan oleh Watagula's pada tahun 1993. Transformasi Sumudu juga merupakan transformasi integral yang dapat digunakan untuk menyelesaikan persamaan diferensial biasa dan masalah rekayasa kontrol [5]. 


\section{PERSAMAAN DIFERENSIAL}

Persamaaan yang melibatkan turunan dari satu atau lebih variabel terikat terhadap variabel bebas disebut persamaan diferensial [6]. Suatu persamaan diferensial biasa

$$
F\left(x, y, y^{\prime}, \cdots y^{(n)}\right)=0
$$

dikatakan linear jika $F$ adalah linear dalam variabel-variabel $x, y, y^{\prime}, \cdots, y^{(n)}$.

Definisi 1 [6] Persamaan diferensial biasa linear orde $n$ dengan $x$ merupakan variabel bebas dan $y$ sebagai variabel terikat, dapat dituliskan sebagai berikut:

$$
a_{n}(x) y^{(n)}+a_{n-1}(x) y^{(n-1)}+\cdots+a_{1}(x) y^{\prime}+a_{0}(x) y=b(x) .
$$

Jika $b(x)=0$ maka Persamaan (6) disebut PDB linear homogen, sedangkan jika $b(x) \neq 0$ maka Persamaan (1) disebut PDB linear nonhomogen.

Contoh 2 Klasifikasi persamaan diferensial.

$$
\begin{aligned}
& y^{\prime \prime \prime}+y^{\prime}+y=0 \\
& y^{\prime \prime}+4 y=2 \sin (x) \\
& U_{x x}+U_{y y}=0
\end{aligned}
$$

Dari Contoh 2 dapat diketahui bahwa Persamaan (2) merupakan PDB linear orde 3 homogen, Persamaan (3) merupakan PDB linear orde 2 nonhomogen dan Persamaan (4) merupakan PDP orde 1. Selain persamaan diferensial linear orde $n$ nonhomogen, fungsi Green juga dapat menyelesaikan persamaan Euler-Cauchy orde dua, dengan mengubah terlebih dahulu persamaan Euler-Cauchy orde dua tersebut ke bentuk persamaan diferensial linear orde dua koefisien konstanta.

\section{FUNGSI GREEN PADA PERSAMAAN DIFERENSIAL}

Fungsi Green merupakan salah satu metode penyelesaian yang dapat digunakan untuk menyelesaikan persamaan diferensial dengan mengkonstruksinya terlebih dahulu. Fungsi Green untuk masalah nilai awal dapat dikonstruksi dengan menggunakan metode transformasi Sumudu.

Fungsi $G(x, t)$ dikatakan fungsi Green untuk masalah nilai awal pada Persamaan (1) jika memenuhi kondisi berikut ini [4]:

1. $G(x, t)$ terdefinisi pada daerah $R=I \times I$ dari semua titik $(x, t)$ dengan $x$ dan $t$ terletak dalam selang $I$.

2. $G(x, t), \frac{\partial G}{\partial x}, \frac{\partial^{2} G}{\partial x^{2}}, \cdots, \frac{\partial^{n} G}{\partial x^{n}}$ merupakan fungsi yang kontinu pada $R=I \times I$.

3. Untuk setiap $x_{0}$ dalam selang $I$ dan fungsi $f \in C(I)$, fungsi $y_{p}(x)=\int_{x_{0}}^{x} G(x, t) f(t) d t$ adalah solusi Persamaan (1) yang memenuhi syarat awal.

\section{TRANSFORMASI SUMUDU}

Transformasi Sumudu merupakan salah satu metode yang dapat digunakan untuk menyelesaikan persamaan diferensial biasa. Transformasi Sumudu juga merupakan salah satu bentuk transformasi yang berbasis integral dan didefinisikan untuk fungsi orde eksponensial. Misalkan fungsi $f$ pada himpunan $A$ didefinisikan sebagai berikut

$$
A=\left\{f(x)\left|\exists M, \tau_{1}, \tau_{2}>0,\right| f(x) \mid<M e^{|x|} / \tau_{j}, x \in(-1)^{j} \times[0, \infty)\right\}
$$

dengan $M$ merupakan konstanta dan $\tau_{1}, \tau_{2}$ dapat bernilai berhingga ataupun tak berhingga [7]. Diasumsikan bahwa fungsi $f$ merupakan fungsi dari $x$ dan didefinisikan transformasi Sumudu sebagai berikut [8]

$$
F(z)=\mathbb{S}[f(x)]=\frac{1}{z} \int_{0}^{\infty} e^{-x / z} f(x) d x .
$$

Contoh 3 Tentukan transformasi Sumudu dari $f(x)=e^{-2 x}$

\section{Penyelesaian:}

Transformasi Sumudu dari $f(x)=e^{-2 x}$, dengan menggunakan Persamaan (5). 


$$
\begin{aligned}
\mathbb{S}\left[e^{-2 x}\right] & =\frac{1}{z} \int_{0}^{\infty} e^{-x / z} e^{-2 x} d x \\
& =\frac{1}{z} \lim _{a \rightarrow \infty} \int_{0}^{a} e^{\frac{x(-1-2 z)}{z}} d x \\
& =\frac{1}{z} \lim _{a \rightarrow \infty}\left(\frac{z}{(-1-2 z)} e^{\left.\frac{x(-1-2 z)}{z}\right|_{0} ^{a}}\right) \\
& =\frac{1}{z}\left[\lim _{a \rightarrow \infty}\left(\frac{z}{(-1-2 z)} e^{\frac{a(-1-2 z)}{z}}-\frac{z}{(-1-2 z)}\right)\right] \\
& =\frac{1}{1+2 z}
\end{aligned}
$$

Jadi transformasi Sumudu dari $f(x)=e^{-2 x}$ adalah $\frac{1}{1+2 z}$.

Salah satu sifat pada transformasi $S$ Sumudu yaitu sifat konvolusi yang mana sifat tersebut digunakan untuk mendapatkan fungsi Green.

Definisi 4 [9] Jika $f$ dan $g$ fungsi pada $\mathbb{R}$ maka konvolusi dari fungsi $f * g$ didefinisikan sebagai berikut

$$
(f * g)(x)=\int f(x-y) g(y) d y .
$$

Misalkan $x-y=z$ maka $y=x-z$ sehingga berlaku $(g * f)(x)$ dengan kata lain [9].

$$
(g * f)(x)=\int f(z) g(x-z) d z \text {. }
$$

Adapun bentuk teorema konvolusi pada transformasi $S u m u d u$ sebagai berikut.

Teorema 5 [7] Misalkan $M(z)$ dan $N(z)$ adalah transformasi Sumudu masing-masing dari fungsi $f(x)$ dan $g(x)$, maka konvolusi dari fungsi $f$ dan $g$ adalah

$$
\mathbb{S}[(f * g)(x)]=z M(z) N(z) \text {. }
$$

\section{Bukti:}

Diketahui $M(z)$ dan $N(z)$ merupakan masing-masing transformasi Sumudu dari fungsi $f(x)$ dan $g(x)$. Misalkan

$$
\begin{aligned}
& M(z)=\frac{1}{z} \int_{0}^{\infty} f(v) e^{-\frac{v}{u}} d v \\
& N(z)=\frac{1}{z} \int_{0}^{\infty} g(w) e^{-\frac{w}{z}} d w
\end{aligned}
$$

Akan ditunjukkan bahwa $\mathbb{S}[(f * g)(x)]=z M(z) N(z)$

$$
\begin{aligned}
z M(z) N(z) & =z\left[\left(\frac{1}{z} \int_{0}^{\infty} f(v) e^{-\frac{v}{z}} d v\right)\left(\frac{1}{z} \int_{0}^{\infty} g(w) e^{-\frac{w}{z}} d w\right)\right] \\
& =z\left[\frac{1}{z} \frac{1}{z}\left(\int_{0}^{\infty} \int_{0}^{\infty} f(v) g(w) e^{-\frac{(v+w)}{z}} d v d w\right)\right]
\end{aligned}
$$

Misalkan 1: $x=v+w$ maka $w=x-v$

$$
\begin{aligned}
& =\left[\frac{1}{z}\left(\int_{x=0}^{\infty} \int_{v=0}^{x} f(v) g(x-v) e^{-\frac{x}{z}} d v d x\right)\right] \\
& =\left[\frac{1}{z} \int_{x=0}^{\infty} e^{-\frac{x}{z}} \int_{v=0}^{x} f(v) g(x-v) d v d x\right]
\end{aligned}
$$

Misalkan 2: $\tau=v$ maka $d \tau=d v$ dengan $v \in[0, x]$ 


$$
\begin{aligned}
& =\left[\frac{1}{z} \int_{0}^{\infty} e^{-\frac{x}{z}} \int_{0}^{x} f(\tau) g(x-\tau) d \tau d x\right] \\
& =\mathbb{S}\left[\int_{0}^{x} f(\tau) g(x-\tau) d \tau\right]=\mathbb{S}[(f * g)(x)] .
\end{aligned}
$$

\section{INVERS TRANSFORMASI SUMUDU}

Jika transformasi Sumudu dari $f(x)$ adalah $F(z)$ maka fungsi $f(x)$ merupakan invers transformasi Sumudu dari $F(z)$ dengan notasi sebagai berikut [8]

$$
f(x)=\mathbb{S}^{-1}[F(z)]
$$

Berdasarkaan Persamaan (5), diperoleh transformasi Sumudu dari beberapa fungsi yang disajikan pada Tabel 1 [7].

Tabel 1. Transformasi Sumudu dari Beberapa Fungsi

\begin{tabular}{|c|c|c|}
\hline No & $f(x)$ & $\mathbb{S}[f(x)]=F(z)$ \\
\hline 1. & 1 & 1 \\
\hline 2. & $x$ & $\frac{1}{1-a z}$ \\
\hline 3. & $e^{a x}$ & $\frac{z}{(1-a z)^{2}}$ \\
\hline 4. & $x e^{a x}$ & $\frac{z}{1+z^{2}}$ \\
\hline 5. & $\sin x$ & $\frac{1}{1+z^{2}}$ \\
\hline 6. & $\cos x$ & $\frac{a z}{1+a^{2} z^{2}}$ \\
\hline 7. & $\sin a x$ & $\frac{1}{1+a^{2} z^{2}}$ \\
\hline 8. & $\cos a x$ & $\frac{z}{(1-a z)^{2}+\omega^{2} z^{2}}$ \\
\hline 9. & $\frac{1}{\omega} e^{a x} \sin \omega x$ & $\frac{1-a z}{(1-a z)^{2}+\omega^{2} z}$ \\
\hline 10. & $e^{a x} \cos \omega x$ & \\
\hline
\end{tabular}

\section{MENGKONSTRUKSI FUNGSI GREEN DARI PERSAMAAN DIFERENSIAL BIASA LINEAR ORDE $n$}

Pada penelitian ini, konstruksi fungsi Green dari PDB linear orde $n$ dengan metode transformasi Sumudu. Diberikan PDB linear orde $n$ nonhomogen dengan koefisien konstanta

dengan $a_{n} \neq 0$.

$$
a_{n} y^{(n)}+a_{n-1} y^{(n-1)}+\cdots+a_{1} y^{\prime}+a_{0} y=b(x)
$$

Transformasi Sumudu dari Persamaan (6) sebagai berikut

$$
\begin{aligned}
& \mathbb{S}[y(x)]=Y(z) \\
& \mathbb{S}\left[y^{(k)}(x)\right]=\frac{Y(z)}{z^{k}}-\frac{y(0)}{z^{k}}-\cdots-\frac{y^{(k-4)}(0)}{z^{4}}-\frac{y^{(k-3)}(0)}{z^{3}}-\frac{y^{(k-2)}(0)}{z^{2}}-\frac{y^{(k-1)}(0)}{z}, \text { untuk } k \in\{1,2, \cdots, n\} .
\end{aligned}
$$

dengan syarat awal $y^{(n-1)}(0)=y^{(n-2)}(0)=\cdots=y(0)=0$, maka diperoleh

$$
\begin{aligned}
& \mathbb{S}\left[y^{(k)}(x)\right]=\frac{1}{z^{k}} Y(z), \text { untuk } k \in\{1,2, \cdots, n\} . \\
& \mathbb{S}[y(x)]=Y(z)
\end{aligned}
$$

Selanjutnya substitusi Persamaan (7) dan (8) ke Persamaan (6) dengan $\mathbb{S}[b(x)]=B(z)$ sehingga diperoleh

$$
\begin{aligned}
& a_{n} \frac{1}{z^{n}} Y(z)+a_{n-1} \frac{1}{z^{n-1}} Y(z)+\cdots+a_{1} \frac{1}{z} Y(z)+a_{0} Y(z)=B(z) \\
& Y(z)\left(\frac{a_{n}}{z^{n}}+\frac{a_{n-1}}{z^{n-1}}+\cdots+\frac{a_{1}}{z}+a_{0}\right)=B(z)
\end{aligned}
$$




$$
\begin{aligned}
& Y(z)\left(\frac{a_{n}+a_{n-1} z+\cdots+a_{1} z^{n-1}+a_{0} z^{n}}{z^{n}}\right)=B(z) \\
& Y(z)=\left(\frac{z^{n}}{a_{n}+a_{n-1} z+\cdots+a_{1} z^{n-1}+a_{0} z^{n}}\right) B(z) \\
& Y(z)=z\left(\frac{z^{n-1}}{a_{n}+a_{n-1} z+\cdots+a_{1} z^{n-1}+a_{0} z^{n}}\right) B(z) \\
& Y(z)=z W(z) B(z) .
\end{aligned}
$$

Berdasarkan definisi transformasi Sumudu yaitu Persamaan (5) maka $B(z)$ merupakan transformasi Sumudu dari $b(x)$ dan $W(z)$ merupakan transformasi Sumudu dari $w(x)$. Kemudian, dengan teorema konvolusi yaitu Teorema 5 dengan $B(z)$ dan $W(z)$ yang merupakan masing-masing transformasi Sumudu dari $b(x)$ dan $w(x)$ berlaku

$$
\begin{aligned}
z W(z) B(z) & =\mathbb{S}[(b * w)(x)] \\
& =\mathbb{S}\left[\int_{0}^{x} b(t) w(x-t) d t\right]
\end{aligned}
$$

sehingga diperoleh

$$
Y(z)=\mathbb{S}\left[\int_{0}^{x} b(t) w(x-t) d t\right],
$$

dengan menggunakan invers transformasi Sumudu maka

$$
\begin{aligned}
y(x) & =\mathbb{S}^{-1}[Y(z)] \\
& =\mathbb{S}^{-1}\left(\mathbb{S}\left[\int_{0}^{x} b(t) w(x-t) d t\right]\right) \\
& =\int_{0}^{x} b(t) w(x-t) d t .
\end{aligned}
$$

Dengan demikian diperoleh bentuk fungsi Green untuk Persamaan (6) dengan metode transformasi Sumudu, yaitu

$$
w(x)=\mathbb{S}^{-1}\left[\frac{z^{n-1}}{a_{n}+a_{n-1} z+\cdots+a_{1} z^{n-1}+a_{0} z^{n}}\right]
$$

dengan $y(x)=\int_{0}^{x} b(t) w(x-t) d t$ merupakan solusi untuk Persamaan (6).

Contoh 6 Tentukan penyelesaian dari persamaan diferensial $y^{\prime}=x$ dengan nilai awal $y(0)=0$ menggunakan metode fungsi Green yang telah dikonstruksi.

\section{Penyelesaian:}

Diketahui persamaan diferensial $y^{\prime}=x$ dengan $a_{1}=1, a_{0}=0$ maka diperoleh $w(x)$ sebagai berikut

$$
\begin{aligned}
w(x) & =\mathbb{S}^{-1}\left[\frac{z^{1-1}}{1+0}\right] \\
& =1
\end{aligned}
$$

Jadi,

$$
\begin{aligned}
y(x) & =\int_{0}^{x} b(t) w(x-t) d t \\
& =\int_{0}^{x} t .1 d t \\
& =\left.\frac{1}{2} t^{2}\right|_{0} ^{x}=\frac{1}{2} x^{2} .
\end{aligned}
$$


Contoh 7 Tentukan penyelesaian dari persamaan diferensial $y^{\prime \prime}+y^{\prime}=x$ dengan nilai awal $y(0)=$ $y^{\prime}(0)=0$ menggunakan metode fungsi Green yang telah dikonstruksi.

\section{Penyelesaian:}

Diketahui persamaan diferensial $y^{\prime \prime}+y^{\prime}=x$ dengan $a_{2}=1, a_{1}=1$, dan $a_{0}=0$ maka diperoleh $w(x)$ sebagai berikut

Jadi,

$$
\begin{aligned}
w(x) & =\mathbb{S}^{-1}\left[\frac{z}{1+z}\right] \\
& =\mathbb{S}^{-1}\left[1-\frac{1}{1+z}\right] \\
& =\mathbb{S}^{-1}[1]-\mathbb{S}^{-1}\left[\frac{1}{1+z}\right] \\
& =1-\left(e^{-x}\right)
\end{aligned}
$$

$$
\begin{aligned}
y(x) & =\int_{0}^{x} b(t) w(x-t) d t \\
& =\int_{0}^{x} t\left(1-e^{-(x-t)}\right) d t \\
& =\frac{1}{2} t^{2}-t e^{(t-x)}+\left.e^{(t-x)}\right|_{0} ^{x} \\
& =\frac{1}{2} x^{2}-x+1-e^{-x}
\end{aligned}
$$

Contoh 8 Tentukan penyelesaian dari persamaan diferensial $y^{\prime \prime \prime}+y^{\prime}=x$ dengan nilai awal $y(0)=$ $y^{\prime}(0)=y^{\prime \prime}(0)=0$ menggunakan metode fungsi Green yang telah dikonstruksi.

\section{Penyelesaian:}

Diketahui persamaan diferensial $y^{\prime \prime \prime}+y^{\prime}=x$ dengan $a_{3}=1, a_{2}=0, a_{1}=1$, dan $a_{0}=0$ maka diperoleh $w(x)$ sebagai berikut

$$
\begin{aligned}
w(x) & =\mathbb{S}^{-1}\left[\frac{z^{2}}{1+z^{2}}\right] \\
& =\mathbb{S}^{-1}\left[1-\frac{1}{1+z^{2}}\right] \\
& =\mathbb{S}^{-1}[1]-\mathbb{S}^{-1}\left[\frac{1}{1+z^{2}}\right] \\
& =1-\cos x .
\end{aligned}
$$

Jadi,

$$
\begin{aligned}
y(x) & =\int_{0}^{x} b(t) w(x-t) d t \\
& =\int_{0}^{x} t(1-\cos (x-t)) d t \\
& =\int_{0}^{x} t[1-(\cos x \cos t+\sin x \sin t)] d t \\
& =\int_{0}^{x} t d t-\cos x \int_{0}^{x} t \cos t d t-\sin x \int_{0}^{x} t \sin t d t \\
& =\left.\frac{1}{2} t^{2}\right|_{0} ^{x}-\cos x\left(t \sin t+\left.\cos t\right|_{0} ^{x}\right)-\sin x\left(\sin t-\left.t \cos t\right|_{0} ^{x}\right) \\
& =\frac{1}{2} x^{2}+\cos x-1
\end{aligned}
$$


Contoh 9 Tentukan penyelesaian persamaan Euler-Cauchy berikut ini dengan nilai awal $y(1)=$ $y^{\prime}(1)=0$ menggunakan metode fungsi Green yang telah dikonstruksi

$$
x^{2} \frac{d^{2} y}{d x^{2}}-5 x \frac{d y}{d x}+8 y=x
$$

\section{Penyelesaian:}

Dengan mensubstitusikan $x^{2} \frac{d^{2} y}{d x^{2}}=\frac{d^{2} y}{d s^{2}}-\frac{d y}{d s}, x \frac{d y}{d x}=\frac{d y}{d s}$ dan $x=e^{s}$ maka diperoleh persamaan diferensial linear nonhomogen sebagai berikut

$$
\frac{d^{2} y}{d s^{2}}-6 \frac{d y}{d s}+8 y=e^{s}
$$

Diketahui persamaan diferensial $y^{\prime \prime}-6 y^{\prime}+8 y=e^{s}$ dengan $a_{2}=1, a_{1}=-6$, dan $a_{0}=8$ maka diperoleh $w(s)$ sebagai berikut

$$
w(s)=\mathbb{S}^{-1}\left[\frac{z}{1-6 z+8 z^{2}}\right]=\mathbb{S}^{-1}\left[\frac{z}{(1-4 z)(1-2 z)}\right]=\frac{1}{2}\left(e^{4 s}-e^{2 s}\right)
$$

Jadi,

$$
\begin{aligned}
y(s) & =\int_{0}^{s} b(t) w(s-t) d t \\
& =\int_{0}^{s} e^{t}\left(\frac{1}{2}\left(e^{4(s-t)}-e^{2(s-t)}\right)\right) d t \\
& =\int_{0}^{s} e^{t}\left(\frac{1}{2} \frac{e^{4 s}}{e^{4 t}}-\frac{1}{2} \frac{e^{2 s}}{e^{2 t}}\right) d t \\
& =\frac{1}{2} e^{4 s} \int_{0}^{s} \frac{1}{e^{3 t}} d t-\frac{1}{2} e^{2 s} \int_{0}^{s} \frac{1}{e^{t}} d t \\
& =\frac{1}{2} e^{4 s}\left(-\left.\frac{1}{3} e^{-3 t}\right|_{0} ^{s}\right)-\frac{1}{2} e^{2 s}\left(-\left.e^{-t}\right|_{0} ^{s}\right) \\
& =\frac{1}{2} e^{4 s}\left(-\frac{1}{3} e^{-3 s}+\frac{1}{3}\right)-\frac{1}{2} e^{2 s}\left(-e^{-s}+1\right) \\
& =\frac{1}{6} e^{4 s}+-\frac{1}{2} e^{2 s}+\frac{1}{3} e^{s} .
\end{aligned}
$$

Jadi diperoleh penyelesaian untuk persamaan Euler-Cauchy $x^{2} \frac{d^{2} y}{d x^{2}}-5 x \frac{d y}{d x}+8 y=x$ yaitu

$$
y(x)=\frac{1}{6} x^{4}-\frac{1}{2} x^{2}+\frac{1}{3} x .
$$

\section{KESIMPULAN}

Berdasarkan hasil penelitian ini dapat disimpulkan bahwa:

1. Fungsi Green untuk persamaan diferensial biasa linear orde $n$ nonhomogen dengan nilai awal $y^{(n-1)}(0)=y^{(n-2)}(0)=\cdots y(0)=0$ menggunakan transformasi Sumudu yaitu

$$
w(x)=\mathbb{S}^{-1}\left[\frac{z^{n-1}}{\left(a_{n}+a_{1} z+\cdots+a_{n-1} z^{n-1}+a_{0} z^{n}\right)}\right]
$$

2. Fungsi Green yang diperoleh dapat digunakan untuk menyelesaikan persamaan diferensial biasa linear nonhomogen dengan nilai awal $y^{(n-1)}(0)=y^{(n-2)}(0)=\cdots=y(0)=0$ yaitu

$$
y(x)=\int_{0}^{x} b(t) w(x-t) d t
$$




\section{DAFTAR PUSTAKA}

[1] Pinem MD. Kalkulus untuk Perguruan Tinggi. Rekayasa Sains: Bandung; 2015

[2] Duffy DG. Green's Functions with Applications, Second Edition. Taylor and Francis Group: USA; 2015.

[3] Alwi W, Abidin W, Ratnasari. Fungsi Green yang Dikontruksi pada Persamaan Diferensial Linear Tak Homogen Orde n. MSA. 3(1): 21-28, 2015.

[4] Djauhari E. Membangun Fungsi Green dari Persamaan Linear Nonhomogen Tingkat $\mathrm{n}$. Matematika Integratif. 11(2): 119-126, 2015.

[5] Kilicman A, Gupta VG, Sharama B. On the Solution of Fractional Maxwell Equations by Sumudu Transform, Journal of Mathematics Research. 2(4), 2010.

[6] Ross SL. Differential Equation, Third Edition. John Wiley and Sons Inc: New Delhi; 2010

[7] Belgacem FBM, Karaballi AA, Kalla SL. Analytical Investigations of the Sumudu Transform, and Applications To Integral Production Equations, Mathematical Problems in Engineering (MPE). (3):103-118, 2003.

[8] Zhang J. A Sumudu Based Algorithm for Solving Differential Equations, Computer Science Journal of Moldova. 15(3):45, 2007

[9] Folland GB. Fourier Analysis and its Applications. Wadsworth Inc: Amerika; 1992

MAISURAH

HELMI

YUDHI
: Jurusan Matematika FMIPA Untan, Pontianak, maisurah133@gmail.com

: Jurusan Matematika FMIPA Untan, Pontianak, helmi132205@yahoo.co.id

: Jurusan Matematika FMIPA Untan, Pontianak, yudhi@math.untan.ac.id 